\title{
Synthesis of monodispersed model catalysts using softlanding cluster deposition*
}

\author{
Stéphane Abbet ${ }^{1}$, Ken Judai ${ }^{1}$, Laurent Klinger $^{2}$, and Ueli Heiz ${ }^{1, \ddagger}$ \\ ${ }^{1}$ University of Ulm, Institute of Surface Chemistry and Catalysis, Albert-Einstein- \\ Allee 47, 89069 UIm, Germany; ${ }^{2}$ Ecole Polytechnique Fédérale de Lausanne, \\ CRPP, 1015 Lausanne, Switzerland
}

\begin{abstract}
In nanocatalysis, clusters deposited on solid, well-defined surfaces play an important role. For the detection of size effects it is, however, important to prepare samples consisting of deposited clusters of a single size, as their chemical properties change with the exact number of atoms in the cluster. In this paper, the experimental tools are presented to prepare such model systems. The existence of monodispersed clusters is confirmed by various experimental findings. First, the carbonyl formation of deposited $\mathrm{Ni}_{n}$ clusters shows no change in the nuclearity when comparing the size of the deposited clusters with one of the formed carbonyls. Second, scanning tunneling microscopy (STM) studies show that fragmentation of $\mathrm{Si}_{n}$ clusters upon deposition can be excluded. In addition, the adsorption behavior of $\mathrm{CO}$ on deposited $\mathrm{Pd}$ atoms points to the existence of single atoms on the surface. Furthermore, $\mathrm{CO}$ oxidation results on $\mathrm{Au}_{n}$ clusters confirm the existence of monodispersed clusters trapped on well-defined adsorption sites. Finally, we use Monte-Carlo simulations to define the range of clusters and defect densities, for which monodispersed clusters can be expected.
\end{abstract}

\section{INTRODUCTION}

Since 1960, studies of elementary chemical processes on single-crystal surfaces have contributed substantially to the understanding of heterogeneous catalysis [1], but two gaps between real catalysis and traditional surface science have been identified: the material gap and the pressure gap [2]. In order to bridge the first one, Poppa introduced, 20 years ago, model catalysts consisting of small particles on oxide surfaces [3]. The metal particles were generated by growth, leading to particle sizes of hundreds or thousands of atoms. Many studies were devoted to these systems and revealed particle-size-dependant behavior of several catalytic reactions [4-9]. Up to now, however, studies on particle sizes below $1 \mathrm{~nm}$ are rare [10], although such small particles, called clusters, were identified in real catalysts. As an example, Nellist and Pennycook have shown by scanning transmission electron microscopy that clusters of two and three Pt atoms exist in naphtha reforming catalysts [11].

The main obstacle to undertaking studies in this size domain was the impossibility of preparing a collection of supported metal clusters that are truly monodispersed, i.e., they all have exactly the same size [12]. Indeed, this condition is needed when one wants to understand size-dependent catalytic properties of these metal clusters. Moreover, it is well known that for nanoclusters containing only a few atoms, quantum size effects become dominant [13] and their physical [14-19] and chemical [20] properties drastically depend on the number of atoms per cluster.

*Pure Appl. Chem. 74, 1489-1783 (2002). An issue of reviews and research papers based on lectures presented at the $2^{\text {nd }}$ IUPAC Workshop on Advanced Materials (WAM II), Bangalore, India, 13-16 February 2002, on the theme of nanostructured advanced materials.

${ }^{\ddagger}$ Corresponding author 
Curious about investigating this unexplored field, we succeeded in preparing model catalysts consisting of a collection of metal clusters of a single size. These model catalysts, which we call nanocatalysts [21], are fabricated by softlanding size-selected metal clusters on oxide supports. We showed that these systems exhibit strongly size-dependent efficiencies and selectivities for, e.g., the $\mathrm{CO}$ combustion on small metal clusters [22-24] or the polymerization of acetylene on supported palladium clusters [25-27].

In this study, we focus on the synthesis and characterization of these monodispersed model catalysts and describe the experimental conditions needed for the preparation of quasi-monodispersed cluster samples. In the second section, we describe briefly cluster generation and growth of the cluster support material, i.e., thin magnesium oxide films. In the third section, we present results of the characterization of these $\mathrm{MgO}(100)$ thin films. In addition, results are presented that evidence the softlanding of the clusters. Monte-Carlo simulations define the densities of clusters and defect sites for which monodispersed clusters can be expected. Finally, in the fourth section, four examples are presented indicating experimentally the existence of quasi-monodispersed supported clusters.

\section{METHOD}

\section{Size-selected clusters production}

The clusters are produced by a high-frequency laser evaporation source [28]. In this source, a cold $\mathrm{He}$ pulse thermalizes the laser-produced plasma. Subsequent supersonic expansion of the helium-metal vapor leads to cold clusters with a narrow kinetic energy distribution. The positively charged cluster ions are guided by home-built ion optics through differentially pumped vacuum chambers, are deflected by $90^{\circ}$ to remove the neutrals from the cluster ion beam and are then size-selected by a quadrupole mass spectrometer (Extrel Merlin System; mass limit: 1000-9000 amu). The clusters are then softlanded on an oxide support under UHV conditions. Depending material and cluster-size ion currents on the sample are hundreds of $\mathrm{pA}$ up to a couple of $\mathrm{nA}$. The source allows for the preparation of clusters of almost all materials, and by using alloyed target materials mixed clusters of different elements can be produced.

\section{Magnesium oxide thin film preparation}

Thin oxide films are especially suitable in their function as support for size-selected metal clusters. Many investigations [29-31] have shown that these thin films exhibit roughly the same chemical and physical proprieties as their bulk analogs. When prepared under UHV conditions, they are atomically clean, important for the investigation of chemical properties of clusters at low coverages. In our experiments, thin $\mathrm{MgO}(100)$ films are used. These films are grown in situ on $\mathrm{Mo}(100)$ by evaporating pure metallic magnesium at an oxygen pressure of $5 \times 10^{-7}$ mbar and by annealing subsequently the oxide film to $1000 \mathrm{~K}[32,33]$.

\section{EXPERIMENTAL AND CHARACTERIZATION}

\section{Characterization of the $\mathrm{MgO}(100)$ support}

As evidenced by Auger electron spectroscopy (AES), the $\sim 10$ monolayer (ML) thick MgO films grown on $\mathrm{Mo}(100)$ show a one-to-one stoichiometry without any carbon impurities [28]. A sharp $(1 \times 1)$ lowenergy electron diffraction (LEED) pattern taken of a typical $\mathrm{MgO}$ film after a short annealing, multiple phonon losses in the high-resolution electron energy loss spectrum (HREELS), the characteristic ultraviolet photoemission (UPS) from the $\mathrm{O} 2 \mathrm{p}$ valence band, as well as the electron energy loss spectra (EELS, see inset of Fig. 4a) with the characteristic loss at about $6 \mathrm{eV}$ indicate a well-ordered $\mathrm{MgO}(100)$ single-crystal surface in good agreement with previous studies [33,34]. Although these 
$\mathrm{MgO}(100)$ films reveal similar properties as observed for the corresponding three-dimensional solids, they expose, depending on the $\mathrm{Mg}$ evaporation rate, $\mathrm{O}_{2}$ background pressure, and annealing temperature, a reproducible density of defects on their surface. The defect density was determined by titration with small molecules like $\mathrm{CO}$ and $\mathrm{NO}$. For $\mathrm{CO}$ chemisorption on $\mathrm{MgO}(100)$ [35], it was concluded from highly accurate first-principle theoretical model calculations that the relatively strong chemisorption energy coupled with an unusual blue shift of the $\mathrm{CO}$ frequency in $\mathrm{CO} / \mathrm{MgO}(100) / \mathrm{Mo}(100)$ reported experimentally [36] cannot correspond to chemisorption on regular, unperturbed five-coordinated sites as claimed. Rather, it was suggested that the unusually strong interaction should be connected with extended defects (steps, kinks) on the oxide film. In fact, assuming one $\mathrm{CO}$ molecule to desorb from each extended defect site, we can estimate the density of this type of defect on the surface. In addition to the extended defect sites, also point defects, e.g., oxygen vacancies (F-centers), are present on the support surface. Recently, Di Valentin et al. have shown that these point defects activate the conversion of $\mathrm{NO}$ to $\mathrm{N}_{2} \mathrm{O}$ on $\mathrm{MgO}(100) / \mathrm{Mo}(100)$ (see inset of Fig. 4b) and are responsible for the high-temperature desorption peak of $\mathrm{NO}$ on $\mathrm{MgO}(100) / \mathrm{Mo}(100)$. If we assume that one $\mathrm{NO} / \mathrm{N}_{2} \mathrm{O}$ desorbs/forms on each point defect, the evaluation of their density is feasible. Taking into account both extended and point defects, all films used for the cluster deposition experiments reveal trapping center densities of at least $2-5 \%$ ML.

\section{Softlanding of clusters}

One concern when using free clusters to prepare monodispersed cluster materials is the fate of the clusters upon deposition onto the solid surface. This collision results in a redistribution of energy after the impact. In this process, the amount of kinetic and internal energy of the cluster, the binding energy between cluster and substrate, as well as an eventual Coulomb energy between the cluster ion and an induced image charge in the target surface are decisive for the degree of melting, disordering, fragmentation, or rebounding of the cluster. In this context, softlanding can be defined as a collision outcome allowing for plastic deformation of the cluster, but not for fragmentation and implantation. Molecular dynamics studies [37-39] have shown that cluster implantation occurs at about $1 \mathrm{eV} /$ atom kinetic energy of the cluster, regardless of the cluster-substrate system. Consequently, this value represents the upper kinetic energy limit for softlanding condition.

The total energy of the deposition process in the experiments presented here is composed of the kinetic energy of the cluster ( $E_{\text {kin }} \leq 0.2 \mathrm{eV} /$ atom) [28], the chemical binding energy between, e.g., $\mathrm{Pd}_{n}$, $\mathrm{Ni}_{n}$, and $\mathrm{Au}_{n}$ clusters and the $\mathrm{MgO}$ surface (0.4-1.4 eV per interacting atom [40]), as well as a negligible Coulomb interaction between the incoming cluster ion and its induced polarization charge on the oxide film surface. Consequently, as the kinetic energies of the impinging clusters correspond to softlanding conditions ( $E_{\text {kin }} \leq 1 \mathrm{eV} /$ atom) and as the total energy gained upon deposition is at least a factor of two smaller than the binding energy of the investigated clusters, ranging from 2.0 to $5 \mathrm{eV}$, fragmentation of the cluster is excluded. From an experimental point of view, small kinetic energies of the clusters are only possible if the cluster source produces clusters with sharp energy distributions, as in this case the clusters can efficiently decelerated. In laser evaporation sources, this is the case as clusters are formed upon a supersonic expansion.

\section{Monodispersion of deposited clusters}

To prepare cluster-assembled materials less than $0.4 \%$ of a ML of size-selected clusters ( $1 \mathrm{ML}=2 \times 10^{15}$ clusters $/ \mathrm{cm}^{2}$ ) are deposited at $90 \mathrm{~K}$, in order to land them isolated on the surface and to prevent agglomeration of the cluster on the surface. Under our experimental condition, the landing and the migration and trapping of the clusters on the surface was investigated with Monte-Carlo simulations. The surface was modeled by an array of $100 \times 100$, where each cell represents an adsorption site (e.g., an oxygen atom). Densities of trapping centers between 1-5\% ML were chosen randomly. Subsequently, cluster 
densities between 0.05 and $0.5 \%$ ML were randomly deposited, and migration to the trapping centers was simulated by random walk. For each simulation, 2000 samples were taken. No interaction between the clusters is assumed as the deposition rate (1 cluster for each $10 \mathrm{~s}$ onto this array) is very low. After landing of the cluster at the surface (shown for $0.5 \%$ ML in Fig. 1a) and subsequent migration to the trapping centers (Fig. 1b), the number of monomers, dimers, and trimers were evaluated. These simulations show that the deposition of less than $0.5 \%$ ML of clusters results in more than $99 \%$ of isolated clusters (adsorbed on regular sites and trapping centers). If migration is excluded (strong cluster-surface interaction), it is however important to deposit the clusters on surfaces with very low defect densities as otherwise an important fraction of the clusters directly land on the defect sites (Fig. 1a). In a second simulation migration of the clusters to trapping centers was included (weak cluster-surface interaction), and Fig. $1 \mathrm{~b}$ shows the percentage of remaining monomers on the surface. In the worst case, where $0.4 \% \mathrm{ML}$ of clusters are deposited on a film with only $2 \% \mathrm{ML}$ of defects, still $90 \%$ of the deposited clusters are isolated. These simple calculations show that the preparation of samples with monodispersed clusters is possible only when a small number of clusters is deposited. In order to prepare clusters on identical adsorption sites it is essential to have supports with very low defect densities if the cluster-support interaction is strong; a high density of defects is, however, needed when the cluster-support interaction is weak.

(a)

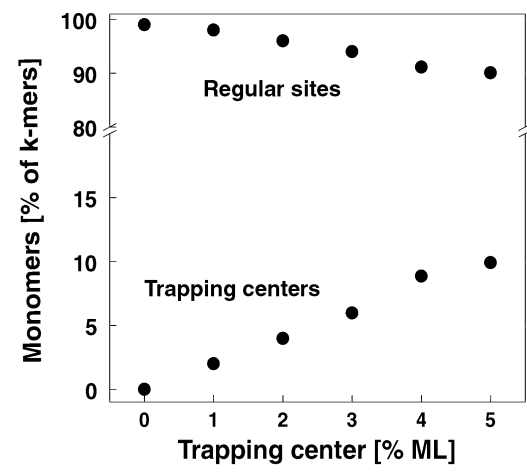

(b)

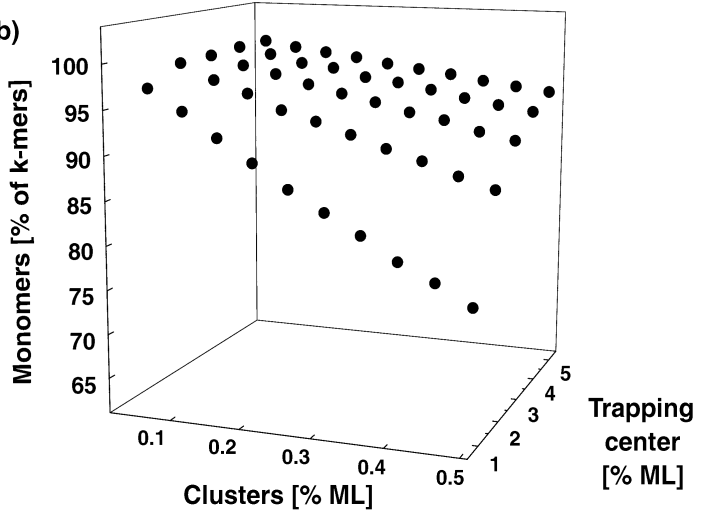

Fig. 1 Monte-Carlo simulation of the cluster deposition process without (a) and with (b) migration. $0.5 \%$ ML of clusters is randomly deposited on an array of $100 \times 100$ adsorption sites (see text). At this coverage, $99 \%$ of the clusters land isolated on the surface. By increasing the trapping center (defect site) density the probability of the cluster to adsorb on different adsorption sites is increasing. At a density of $5 \% \mathrm{ML}, 10 \%$ of the deposited clusters are adsorbed on the trapping centers. Shown are the fraction [\%] of clusters that are isolated after deposition and migration (see text). Increasing the density of trapping centers drastically increases the monodispersion of the clusters. 


\section{EXPERIMENTAL EVIDENCE FOR THE EXISTENCE OF MONODISPERSED CLUSTERS}

\section{Softlanding and monodispersion}

\section{Formation of nickelcarbonyls}

There is experimental evidence for the fact that size-selected clusters deposited at low kinetic energy on oxide films maintain their identity. It is well known that nickel clusters form stable carbonyls. Due to the closed electronic shell of these species, they weakly interact with the support material. Thus, the characterization of the formed nickelcarbonyls can give information on the fate of the clusters after deposition. For this, small deposited $\mathrm{Ni}_{n}(n=1-3)$ clusters were exposed to carbon monoxide and the formed nickelcarbonyls were analyzed by mass spectrometry [41]. These experiments showed that the nuclearity of the formed $\mathrm{Ni}_{n}$ carbonyls $(n=1-3)$ is not changed, indicating that small monodispersed nickel clusters are actually present on the surface. Figure 2 a shows that exclusively $\mathrm{Ni}(\mathrm{CO})_{4}$ is formed after the deposition of $\mathrm{Ni}$ atoms. The absence of, for example, $\mathrm{Ni}(\mathrm{CO})_{4}$ and $\mathrm{Ni}_{3}(\mathrm{CO})$ after deposition of $\mathrm{Ni}_{2}$ directly excludes fragmentation and agglomeration (Fig. $2 \mathrm{~b}$ ).

\section{Imaging size-selected silicon clusters on Ag(111)}

Softlanding of mass-selected $\mathrm{Si}_{30}$ and $\mathrm{Si}_{39}$ clusters on $\mathrm{Ag}(111)$ was observed in recent low-temperature STM experiments [42] performed at kinetic energies well below the softlanding limit and without raregas buffer layers. In these studies, the following findings point toward a nonfragmenting deposition of the clusters. No small $\left(\mathrm{Si}_{1}-\mathrm{Si}_{3}\right)$ and intermediate size $\left(\mathrm{Si}_{6}-\mathrm{Si}_{11}\right)$ clusters were detected, which excludes distinct fragmentation. In addition, the atomically smooth surface adjacent to the clusters showed that no large-scale damage was caused by the impact of the clusters. Furthermore, lateral displacement of the silicon clusters with the STM tip and subsequent imaging of the surface at the impact position revealed no damage at the atomic scale. Consequently, these experiments demonstrate the feasibility of obtaining supported monodispersed metal clusters at low support temperature (90 K) [42].

(a) $2 \% \mathrm{MLNi}_{1}+2 \mathrm{MLCO}$

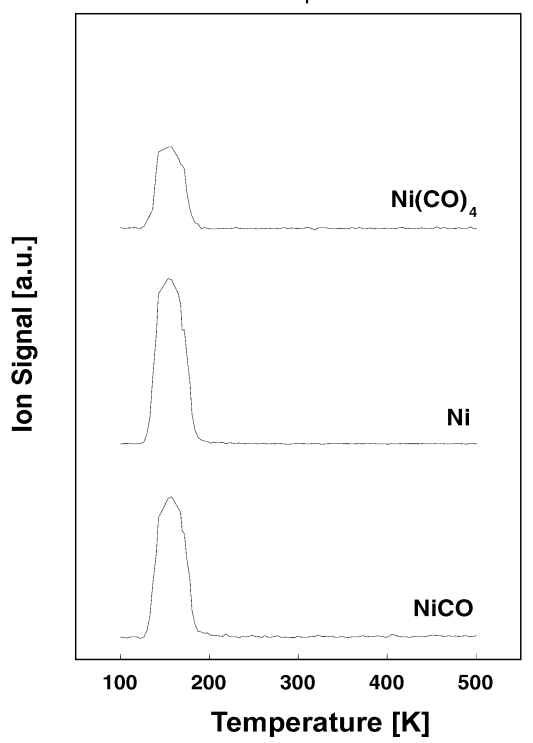

(b) $2 \% \mathrm{ML} \mathrm{Ni}_{2}+2 \mathrm{MLCO}$

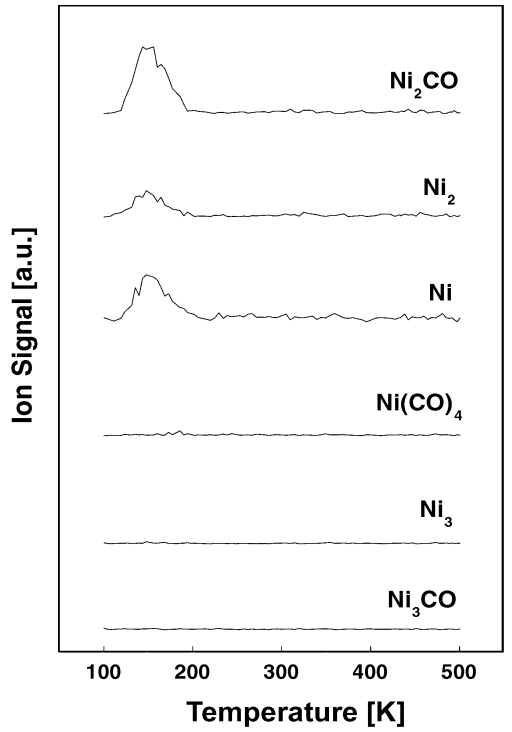

Fig. 2 Formation of nickelcarbonyl after exposing deposited Ni atoms (a) and Ni dimers (b) to CO. Note that for both sizes the nuclearity is not changed, indicating that fragmentation and agglomeration of the Ni species can be excluded. 


\section{Identification of trapping centers}

\section{Adsorption properties of $\mathrm{CO}$ on $\mathrm{Pd}$ atoms}

On a single-crystal $\mathrm{MgO}(100)$ surface with a low concentration of defects, $\mathrm{CO}$ exhibits only one desorption peak at $57 \mathrm{~K}$, which corresponds to $\mathrm{CO}$ weakly bound to terrace sites $\left(E_{\mathrm{b}}=0.14 \mathrm{eV}\right)$ [43]. On a defective $\mathrm{MgO}(100)$ surface, $\mathrm{CO}$ interacts preferentially with defect sites, the low-coordinated $\mathrm{Mg}^{2+}$ cations at steps and kinks [35] and gives rise to a feature in the thermal desorption spectroscopy (TDS) spectrum at $150 \mathrm{~K}$. In the presence of deposited Pd atoms, a weak shoulder appears at around $260 \mathrm{~K}$ due to the desorption of CO from the deposited Pd atoms (Figs. 3a/b). The corresponding binding energy is about $0.7 \mathrm{eV}$, using the Redhead approximation. The supported $\mathrm{Pd}-\mathrm{CO}$ complexes exhibit a ${ }^{12} \mathrm{CO} \omega_{\mathrm{e}}$ of $2055 \mathrm{~cm}^{-1}\left(2010 \mathrm{~cm}^{-1}\right.$ for ${ }^{13} \mathrm{CO}$, Fig. 3c), red-shifted with respect to gas-phase CO by $88 \mathrm{~cm}^{-1}$.

These data provide important information for the identification of the surface sites where the Pd atoms are likely to be trapped*. The $\mathrm{Pd}-\mathrm{CO}$ complexes bound to surface $\mathrm{O}$ anions exhibit a strong $\mathrm{Pd}-\mathrm{CO}$ bond, $>2 \mathrm{eV}$, and a large $\mathrm{CO}$ frequency shift. This rules out the $\mathrm{O}$ anions as the sites where $\mathrm{Pd}$ is bound. This is also consistent with the fact that the binding energy of $\mathrm{Pd}$ atoms on top of the $\mathrm{O}$ anions
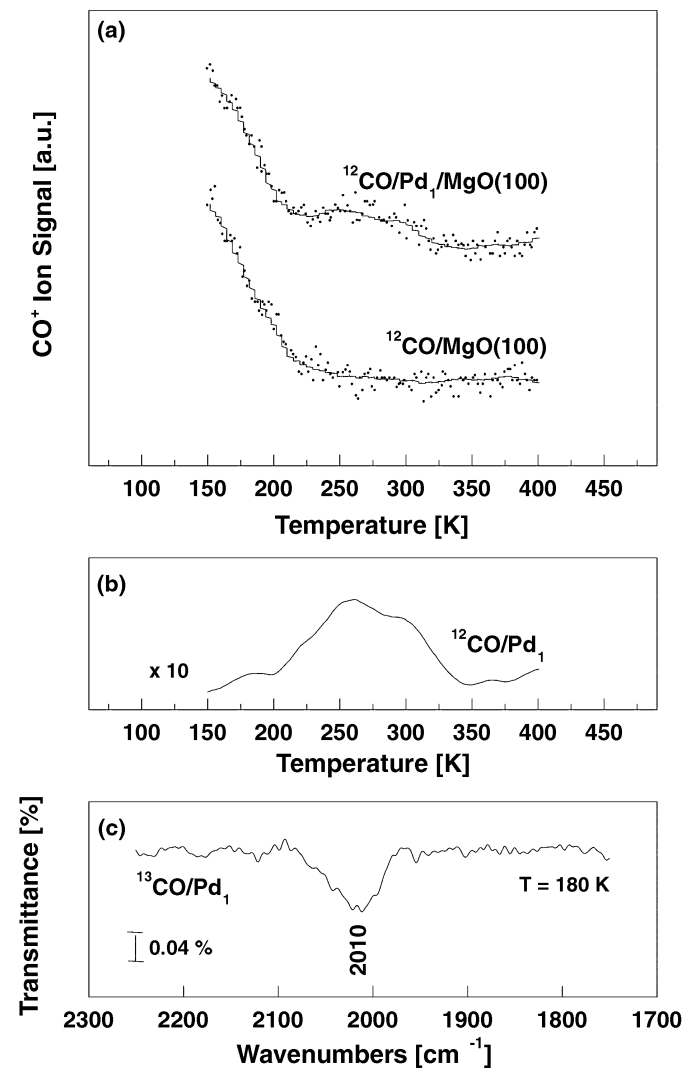

Fig. 3 (a) TDS spectra of $\mathrm{CO}$ from a $\mathrm{MgO}(100)$ thin film covered with $0.4 \%$ ML Pd atoms (upper spectrum) and from a clean $\mathrm{MgO}(100)$ thin film (lower spectrum). Note the desorption peak around $270 \mathrm{~K}$ characteristic for $\mathrm{Pd}$ atoms. (b) Difference spectrum of the CO desorption obtained from the data presented in (a). (c) Vibrational frequency of $\mathrm{CO}$ adsorbed on deposited $\mathrm{Pd}$ atoms. Note that the frequency is measured for ${ }^{13} \mathrm{CO}$. With the known isotopic shift the frequency of ${ }^{12} \mathrm{CO}$ is $2055 \mathrm{~cm}^{-1}$.

\footnotetext{
*When compared to theoretical studies.
} 
is not very high, $1-1.5 \mathrm{eV}$. The diffusion of the $\mathrm{Pd}$ atoms through the $\mathrm{O}-\mathrm{O}$ channels on the surface can imply barriers of $0.5 \mathrm{eV}$ or less [44], suggesting that the Pd atoms are likely to diffuse on the surface until they become trapped by some active defect. The neutral F-centers are very good candidates from this point of view since the binding of Pd to these centers is of the order of $3.5 \mathrm{eV}$. This means that to detrap a Pd atom from one of these sites, a temperature of about $900 \mathrm{~K}$ is required. The Pd-CO units bound to the F-centers exhibit a much weaker Pd-CO bond, of the order of $0.3-0.5 \mathrm{eV}$. This is close to the experimental estimate, $0.7 \mathrm{eV}$, and suggests that the F-centers could be possible adsorption sites for $\mathrm{Pd}$ atoms. On the $\mathrm{F}^{+}$centers, $\mathrm{Pd}$ is bound more strongly than on the $\mathrm{O}$ sites but not as strongly as on the F-centers; the binding energy of $\mathrm{Pd}$ on $\mathrm{F}^{+}$defect centers is consistent with a temperature-induced diffusion of $400 \mathrm{~K}$. The $\mathrm{Pd}-\mathrm{CO}$ complexes at $\mathrm{F}^{+}$sites have bonding characteristics very close to the measured ones. The $\mathrm{Pd}-\mathrm{CO}$ dissociation energy is in fact of $0.6-0.7 \mathrm{eV}$ and a vibrational shift very close to the experimental value.

To summarize, the adsorption properties of $\mathrm{Pd}-\mathrm{CO}$ complexes formed on $\mathrm{MgO}$ thin films cannot be reconciled with the picture of $\mathrm{Pd}$ atoms bound to the surface $\mathrm{O}$ anions, located either on terraces or on low-coordinated sites. Much more consistent with the observation is the hypothesis that the Pd atoms are bound to the oxygen vacancies.

\section{CO oxidation on $\mathrm{Au}_{8}$}

Experimentally, it could be shown that the number of defect sites on the $\mathrm{MgO}$ thin films grown on $\mathrm{Mo}(100)$ is sufficiently high to trap most of the clusters ( $0.4 \% \mathrm{ML})$ under our experimental conditions.
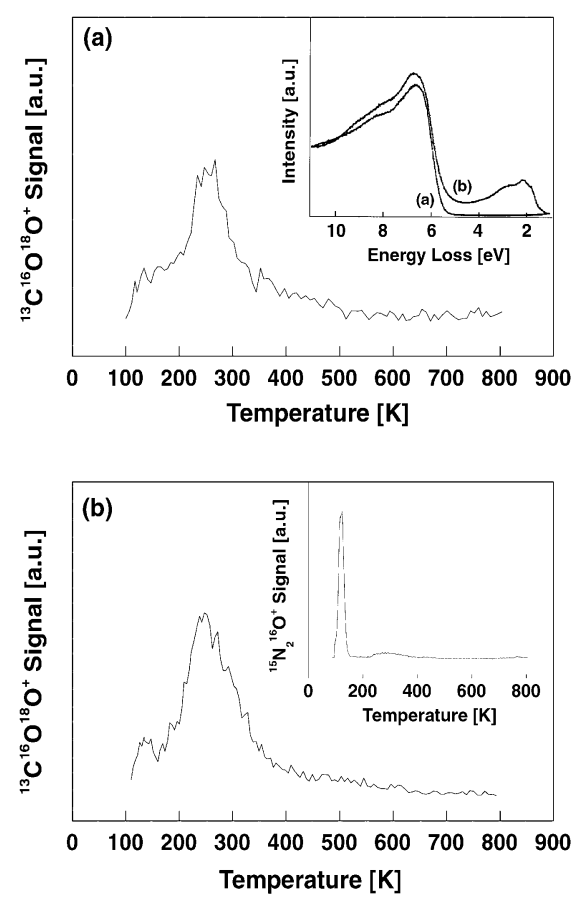

Fig. 4 Formation of $\mathrm{CO}_{2}$ on $\mathrm{Au}_{8}$ deposited on $\mathrm{MgO}(100)$ thin films with different densities of F-centers. (a) The $\mathrm{Au}_{8}$ clusters were deposited on $\mathrm{MgO}(100)$ thin films with a density of F-centers of about $10 \%$ (see text). Clearly, the F-centers can be characterized by the electronic transitions in the band-gap of the oxide measured with EELS (see inset). (b) The clusters are deposited on $\mathrm{MgO}$ thin films with about $2 \% \mathrm{ML}$ of F-centers. The low density of F-centers is characterized by the formation of $\mathrm{N}_{2} \mathrm{O}$ after exposure of 5 Langmuir NO. The formation of $\mathrm{N}_{2} \mathrm{O}$ selectively occurs only on F-centers (see text). Note that on both support materials the formation of $\mathrm{CO}_{2}$ is similar, indicating that $\mathrm{Au}_{8}$ is efficiently trapped on the F-centers. 
It could be shown that for the oxidation of $\mathrm{CO}$ on $\mathrm{Au}_{8} \mathrm{~F}$-centers are necessary for the reaction to occur [22]. The corresponding TDS spectrum for the formed $\mathrm{CO}_{2}$ is shown in Fig. $4 \mathrm{~b}$ and shows a very small desorption peak at around $125 \mathrm{~K}$ and a major desorption peak at $240 \mathrm{~K}$. If the $\mathrm{Au}_{8}$ clusters are adsorbed on a thin film with a small amount of F-centers the formation of $\mathrm{CO}_{2}$ is completely suppressed [22]. In order to judge whether the number of point defect is large enough to trap most of the $\mathrm{Au}_{8}$, one can increase the number of point defects on the $\mathrm{MgO}$ surface. If the number of produced $\mathrm{CO}_{2}$ at constant cluster coverage is constant with increasing number of point defects on the oxide surface then we can conclude that the point defects are not saturated with $\mathrm{Au}_{8}$ clusters. In order to increase the number of F-centers on the $\mathrm{MgO}$ thin films, the method of Peterka et al. can be applied [45]. In this method, the prepared films are exposed to metallic $\mathrm{Mg}$, and after annealing the sample to $500 \mathrm{~K}$ around $10 \% \mathrm{ML}$ F-centers are formed, as detected by EELS measurements (inset of Fig. 4a). Depositing the same amount of $\mathrm{Au}_{8}$ on these films does not enhance the number of formed $\mathrm{CO}_{2}$ (Fig. 4a), thus the defect sites of the naturally grown films are not saturated.

\section{CONCLUSIONS}

We showed the feasibility of the preparation of size-selected clusters on solid surfaces. Two main points are important. First, it is essential to land the clusters with very low kinetic energy ( $E_{\text {kin }}<1 \mathrm{eV} /$ atom) in order to prevent fragmentation upon deposition and with low densities $(<2 \% \mathrm{ML})$. Second, depositing clusters on solid surfaces demands a careful characterization of the support material. If the cluster-support interaction is weak, a high defect density $(\sim 1-5 \% \mathrm{ML})$ results in an efficient trapping of the clusters without coalescence. For strong cluster-support interactions, the defect density has to be kept low in order to land the clusters on identical adsorption sites.

\section{REFERENCES}

1. G. Ertl, H. Knözinger, J. Weitkamp. Handbook of Heterogeneous Catalysis, New York, (1997).

2. G. Ertl and H.-J. Freund. Physics Today 52, 32-38 (1999).

3. H. Poppa. Catal. Rev. Sci. Eng. 35, 359-398 (1993).

4. C. R. Henry. Surf. Sci. Rep. 31, 231-326 (1998).

5. C. T. Campbell Surf. Sci. Rep. 27, 1-111 (1997).

6. D. W. Goodman. Surf. Rev. Lett. 2, 9-24 (1995).

7. H. J. Freund. Angew. Chem., Int. Ed. Engl. 36, 452-475 (1997).

8. J. Bäumer and H. J. Freund. Progr. Surf. Sci. 61, 127 (1999).

9. M. Valden, X. Lai, D. W. Goodman. Science 281, 1647-1650 (1998).

10. M. Boudart. J. Mol. Catal. 30, 27 (1985).

11. P. D. Nellist and S. J. Pennycook. Science 274, 413-415 (1996).

12. G. C. Bond and D. T. Thompson. Catal. Rev.-Sci. Eng. 41, 319-388 (1999).

13. J. Jortner. Z. Phys. D 24, 247 (1992).

14. W. D. Knight, K. Clemenger, W. de Heer, W. A. Saunders, M. Y. Chou, M. L. Cohen. Phys. Rev. Lett. 52, 2141 (1984).

15. E. Schumacher, F. Blatter, M. Frey, U. Heiz, U. Roethlisberger, M. Schaer, A. Vayloyan, C. Yeretzian. Chimia 42, 357-376 (1988).

16. M. D. Morse. Chem. Rev. 86, 1049 (1986).

17. W. A. deHeer. Rev. Mod. Phys. 65, 611-676 (1993).

18. I. M. L. Billas, A. Chatelain, W. A. deHeer. Science 265, 1682 (1994).

19. A. P. Alivisatos. Science 271, 933-937 (1996).

20. A. Kaldor, D. Cox, M. R. Zakin. Adv. Chem. Phys. 70, 211 (1988).

21. U. Heiz and W.-D. Schneider. J. Phys. D (2000). 
22. A. Sanchez, S. Abbet, U. Heiz, W.-D. Schneider, H. Häkkinen, R. N. Barnett, U. Landman. J. Phys. Chem. A 103, 9573-9578 (1999).

23. U. Heiz, A. Sanchez, S. Abbet, W.-D. Schneider. J. Am. Chem. Soc. 121, 3214-3217 (1999).

24. U. Heiz, A. Sanchez, S. Abbet, W.-D. Schneider. Chem. Phys. 262, 189-200 (2000).

25. S. Abbet, A. Sanchez, U. Heiz, W.-D. Schneider, A. M. Ferrari, G. Pacchioni, N. Rösch. Surface Science 454-456, 984-989 (2000).

26. S. Abbet, A. Sanchez, U. Heiz, W.-D. Schneider, A. M. Ferrari, G. Pacchioni, N. Rösch. J. Am. Chem. Soc. 122, 3453-3457 (2000).

27. S. Abbet, A. Sanchez, U. Heiz, W.-D. Schneider. J. Cat. 198, 122-127 (2001).

28. U. Heiz, F. Vanolli, L. Trento, W.-D. Schneider. Rev. Sci. Instrum. 68, 1986 (1997).

29. H. Kuhlenbeck and H.-J. Freund. In Growth and Properties of Ultrathin Epitaxial Layers, Vol. 8, D. A. King and D. P. Woodfuff (Eds.), pp. 340-374, Elsevier Science (1997).

30. S. C. Street, C. Xu, D. W. Goodman. Ann. Rev. Phys. Chem. 48, 43-68 (1997).

31. S. C. Street and D. W. Goodman. Growth and Properties of Ultrathin Epitaxial Layers, Vol. 8, D. A. King and D. P. Woodfuff (Eds.), pp. 375-406, Elsevier Science (1997).

32. M. C. Wu, J. S. Corneille, C. A. Estrada, J.-W. He, D. W. Goodman. Chem. Phys. Lett. 182 (5), $472(1991)$.

33. M.-C. Wu, J. S. Corneille, C. A. Estrada, J.-W. He, D. W. Goodman. J. Vac. Sci. Technol. A 10, 472 (1992).

34. U. Heiz and W. D. Schneider. Crit. Rev. Solid State Mater. Sci. 26, 251-290 (2001).

35. M. A. Nygren and L. G. M. Petterson. J. Phys. Chem. 105, 9339 (1996).

36. J.-W. He, A. E. Cesar, J. S. Corneille, M.-C. Wu, D. W. Goodman. Surf. Sci. 261, 167-170 (1992).

37. H.-P. Cheng and U. Landman. Science 260 1304-1307 (1993).

38. H.-P. Cheng and U. Landman. J. Phys. Chem. 98, 3527 (1994).

39. C. L. Cleveland and U. Landman. Science 257, 355 (1992).

40. I. Yudanov, G. Pacchioni, K. Neyman, N. Roesch. J. Phys. Chem. B 101, 2786-2792 (1997).

41. U. Heiz. Appl. Phys. A 67, 621-626 (1998).

42. S. Messerli, S. Schintke, K. Morgenstern, A. Sanchez, U. Heiz, W.-D. Schneider. Surf. Sci. 465, 331-338 (2000).

43. R. Wichtendahl, M. Rodriguez-Rodrigo, U. Härtel, H. Kuhlenbeck, H.-J. Freund. Surf. Sci. 423, 90-98 (1999).

44. K. M. Neyman, S. Vent, G. Pacchioni, N. Rösch. Nuovo Cimento 19D, 1743 (1997).

45. D. Peterka, C. Tegenkamp, K. M. Schröder, W. Ernst, H. Pfnür. Surf. Sci. 431, 146-155 (1999). 